\title{
Family environment interacts with CRHR1 rs17689918 to predict mental health and behavioral outcomes
}

\section{Arunima Roy ${ }^{\mathrm{a}, *}$, Kariina Laas ${ }^{\mathrm{b}}$, Triin Kurrikoff ${ }^{\mathrm{c}}$, Andreas Reif ${ }^{\mathrm{d}}$, Toomas Veidebaum ${ }^{\mathrm{e}}$, Klaus-Peter Lesch ${ }^{\text {a,f,g, Jaanus Harro }}{ }^{\text {b }}$}

a Division of Molecular Psychiatry, Center of Mental Health, University of Würzburg, Würzburg, Germany

${ }^{\mathrm{b}}$ Division of Neuropsychopharmacology, Department of Psychology, University of Tartu, Tartu, Estonia

${ }^{\mathrm{c}}$ Institute of Social Studies, University of Tartu, Tartu, Estonia

${ }^{\mathrm{d}}$ Department of Psychiatry, Psychosomatic Medicine and Psychotherapy, University Hospital Frankfurt - Goethe University, Frankfurt am Main, Germany

${ }^{\mathrm{e}}$ National Institute for Health Development, Tallinn, Estonia

${ }^{\mathrm{f}}$ Laboratory of Psychiatric Neurobiology, Institute of Molecular Medicine, I.M. Sechenov First Moscow State Medical University, Moscow, Russia

${ }^{\mathrm{g}}$ Department of Translational Neuroscience, School for Mental Health and Neuroscience (MHeNS), Maastricht University, Maastricht, The Netherlands

\footnotetext{
* Corresponding author.

E-mail address: arunima.roy@mail.mcgill.ca (A. Roy).
} 


\begin{abstract}
Background: Corticotrophin-releasing hormone receptor-1 gene (CRHRl) variants have been implicated in mental health. However, little is known of the effects of CRHRI on longterm mental health and behavior in presence of environmental stressors. We assess the effects of $C R H R l$ variant (rs17689918)-by-environment interactions on emotionality and behavioral traits, including anxiety, depression, aggression and antisocial behaviors. We also determine effects of rs17689918-by-environment-by-sex interactions on the above-mentioned outcomes.
\end{abstract} Methods: Genotypic assessments were carried out in 564 children (mean age 10 years, $52.5 \%$ females) from the ongoing longitudinal Estonian Children Personality Behaviour and Health Study (ECPBHS). Information on stressful life events and family relationships were available at baseline and information on behavioral and mental health outcomes (self- and parent-reports) were available at follow-up ages of 18 and 25 years. ANOVAs were used to determine associations of two-way CRHRl-by-environment and three-way CRHRI-by-sexby-environment interactions on behavioral and mental health outcomes.

Results: Two-way CRHRl interaction effects showed associations between low familial warmth and hostility in individuals with the GG genotype. Associations of low familial warmth with aggression, of higher number of stressful life events with aggression, and of stressful live events with anxious-depressive symptoms were noted in male A-allele carriers and female GG homozygotes.

Conclusion: CRHRl-by-familial environment interactions influence both outwardly-directed aggression as well as mood and anxiety disorder symptoms in a sex-specific manner. The type of environmental stressor can also influence effects of $C R H R I$ on behavioral and mental health outcomes. 
Keywords: Corticotrophin releasing hormone receptor-1 (CRHR1), stress, gene-byenvironment interactions (GxE), mood, aggression, family

\section{Introduction}

The hypothalamic-pituitary-adrenocortical (HPA) axis regulates stress responses. A wellfunctioning HPA axis provides resilience to stressful conditions, but some individuals may show maladaptations in stress, and consequently develop mental health problems, such as depression and aggression (Böhnke et al., 2010; Holsboer, 2000; Nestler et al., 2002; Pariante and Miller, 2001). As to how aberrations in the same system, that is the HPA axis, may give rise to divergent outcomes of depression and aggression, is a matter of controversy. Reasons for this may include the type of stressor, genetic constitution or gender differences. In this study, we determine the role of corticotrophin releasing hormone receptor-1 (CRHR1) gene variants and their interactions with stressful life events and family relationships in the development of anxious-depressed and aggressive behavior problems.

Actions of the HPA axis are mediated through the corticotrophin-releasing hormone (CRH). CRH stimulates the receptors, CRHR1 and CRHR2, in the brain, of which CRHR1 will be the focus here as it has implications for mental health (Blomeyer et al., 2008; Liaw et al., 1996; Liu et al., 2006; Nemeroff et al., 1988; Schmid et al., 2010). CRHR1 is widely distributed in the brain, including the hippocampus, striatum, amygdala, as well as the anterior pituitary (Inda et al., 2017). The gene encoding CRHR1, on chromosome 17q21.31 (CRHR1), has been associated with depression (Bradley et al., 2008; da Silva et al., 2016; Liu et al., 2007; Wasserman et al., 2009), especially in presence of stressful life events (Heim et al., 2009; Tyrka et al., 2009; Ressler et al., 2010). There is some evidence that the CRHRI may also be involved in aggression (Chen et al., 2014; De Luca et al., 2010; Merali et al., 2004; Nemeroff et al., 1988). However, most studies have assessed interactions of CRHRI 
with self-directed aggression (De Luca et al., 2010; Merali et al., 2004; Nemeroff et al., 1988; Wasserman et al., 2008) and little information is available on other dimensions of aggression such as bullying, and anti-social behaviors.

The CRHRI may be particularly susceptible to the effects of a negative environment. Enduring Crhrl expression changes have been noted in the hippocampus and amygdala of rodents subjected to early life and peripubertal stress (Veenit et al., 2014). Crhrl expression, especially in the limbic system, is involved in stress responses and underlies the development of anxiety-like behavior in rodents (Müller et al., 2003; Preil et al., 2001; Timpl et al., 1998). Further, blockade of CRHR1 in rodents affects hippocampal development and these receptors mediate the effects of early life stress on spine density, synaptic pruning, and dendritic arborisation (Ivy et al., 2010; Liao et al., 2014; Liu et al., 2016). These results suggest that $C R H R 1$, in presence of stress, may modulate hippocampal- and amygdala-mediated emotional processing and psychopathology (Bremner et al., 2000; Frodl et al., 2002; Ressler, 2010).

Past studies have shown that interactions of $C R H R l$ variants with stress lead to an increased risk for poor mental health outcomes. However, these studies do not distinguish between types of stress. For example, while stressful life events are more likely to predispose towards the development of depressive problems (Power et al., 2013), a lack of maternal or familial warmth is more likely to increase risk for aggressive behaviors (Holmes, 2013). Based on this knowledge, we hypothesized that the eventual effect of $C R H R l$ variants on mental health is dependent on the type of stressor. Further, sex may play a role in the interactions between stress and CRHRI variants and their outcomes; sex-differences are well-established in stress responses (Bale and Epperson, 2015) and sex-specific effects of risk genes are common in mental health outcomes (Ngun et al., 2011; Waller et al., 2016). Therefore, using a large 
prospective population-based cohort, we determine interactions of stress type, CRHRI variants, and sex, and investigate their effects on behavior and mental health.

\section{Methods}

\subsection{Sample}

This study is based on the ongoing longitudinal Estonian Children Personality Behaviour and Health Study (ECPBHS), which includes a younger (mean age of 9 years during sample recruitment) and an older cohort (mean age of 15 years during sample recruitment). To-date, four assessment waves have been completed for both cohorts. The present study uses data only from the younger cohort. Recruitment for the younger cohort began in 1998/99 and this first assessment wave included 583 participants with a mean age of nine years $(55.4 \%$ females). The second, third and fourth waves were in 2004, 2007, and 2014, and included 483 (mean age 15, 54.0\% females) 457 (mean age 18, 56.0\% females), and 441 participants (mean age 25, 56.2\% females) respectively. The present analysis includes 564 participants (52.5\% females) for whom valid genotype data are available. Table 1 presents an overview of the measures included in this paper from each assessment point. All subjects were of European origin. Further details on the cohort are available in previous publications (Harro et al., 2001; Tomson et al., 2011).

The study was approved by the Tartu University Ethics Review Committee on Human Research. Subjects provided written informed consent to participate in the study and all procedures were carried out in accordance with the Declaration of Helsinki.

\subsection{Genotyping}

Qiagen QIAamp®DNA Blood Midi Kit was used to extract genomic DNA from whole blood samples. Genotyping was performed for CRHR1 rs17689918 with the Applied Biosystems 
ViiATM7 Real-Time PCR System. We used the TaqMan®Pre-Designed SNP Genotyping Assay and Solis BioDyne5x HOT FIREPol®Probe qPCR Mix Plus (ROX). Of the total 583 participants in the first wave of the ECPHBS younger cohort, 564 were genotyped. Subjects with the A-allele were combined because of the low number of subjects with the AA genotype ( $\mathrm{n}=7$ ). This led to a total of 414 participants to be classified as GG and 150 participants to be classified as AA/AG.

\subsection{Measures}

Table 1 lists measures available for each wave, and which are described below.

Table 1.

Number of subjects (by gender; $\mathrm{M}=$ males, $\mathrm{F}=$ females) with complete data for CRHR1 rs17689919 and the respective variables included in this study from each wave.

\begin{tabular}{|c|c|c|c|c|}
\hline \multirow{2}{*}{ Measures } & \multicolumn{4}{|l|}{ Study waves } \\
\hline & $9 \mathrm{yrs}$ & $15 \mathrm{yrs}$ & $18 \mathrm{yrs}$ & $25 \mathrm{yrs}$ \\
\hline Stressful life events (SLE) & - & $\mathrm{M}=213, \mathrm{~F}=251$ & - & - \\
\hline Family relations, Warmth & - & $\mathrm{M}=198, \mathrm{~F}=250$ & - & - \\
\hline ADHD teacher's report & $\mathrm{M}=219, \mathrm{~F}=255$ & $\mathrm{M}=180, \mathrm{~F}=208$ & $\mathrm{M}=84, \mathrm{~F}=133$ & - \\
\hline $\begin{array}{l}\text { Buss-Perry Aggression } \\
\text { Questionnaire (BPAQ) }\end{array}$ & - & - & - & $\mathrm{M}=179, \mathrm{~F}=234$ \\
\hline $\begin{array}{l}\text { Affective Neuroscience } \\
\text { Personality Scale (ANPS-S) }\end{array}$ & - & - & - & $\mathrm{M}=179, \mathrm{~F}=234$ \\
\hline $\begin{array}{l}\text { Illinois Bully Scale (IBS) self- } \\
\text { reports }\end{array}$ & - & - & - & $\mathrm{M}=179, \mathrm{~F}=234$ \\
\hline $\begin{array}{l}\text { Illinois Bully Scale (IBS) peer- } \\
\text { reports }\end{array}$ & - & - & - & $\mathrm{M}=229, \mathrm{~F}=263$ \\
\hline $\begin{array}{l}\text { Life History of Aggression } \\
\text { (LHA) interview }\end{array}$ & - & - & - & $\mathrm{M}=180, \mathrm{~F}=233$ \\
\hline Psychiatric M.I.N.I. interview & - & - & - & $\mathrm{M}=182, \mathrm{~F}=234$ \\
\hline $\begin{array}{l}\text { State-Trait Anxiety Inventory } \\
\text { (STAI) State Anxiety }\end{array}$ & - & $M=196, F=238$ & $\mathrm{M}=188, \mathrm{~F}=242$ & $\mathrm{M}=177, \mathrm{~F}=232$ \\
\hline $\begin{array}{l}\text { State-Trait Anxiety Inventory } \\
\text { (STAI) Trait Anxiety }\end{array}$ & - & - & $M=181, F=243$ & $\mathrm{M}=176, \mathrm{~F}=232$ \\
\hline
\end{tabular}

\subsubsection{Predictors}

(i) Stressful life events (SLE) were assessed at age 15 with participant-reports or parentreports on 21-items, which included events such as, parental death, parental divorce or separation, absence of both parents, familial unemployment, financial difficulties and poverty, poor living conditions, poor health and chronic diseases, serious illness of a family 
member, death of a close relative, trauma, fear of school, bullying at school and humiliation at home (Laas et al., 2014). Events were coded dichotomously and total counts across all events represented experienced SLEs. Subjects were divided into low and high SLE groups by median split. (ii) Familial warmth and maltreatment was assessed at age 15 using the child-reported Tartu Family Relationships Scale or TFRS (Kiive et al., 2010; Paaver et al., 2008). The TFRS was created for the ECPBHS cohort (Cronbach's $\alpha$ between 0.80 and 0.94 ) and measures four dimensions of family functioning: closeness (15 items with responses measured to statements such as "Our family is dedicated to each other", "The marriage of my parents is happy"); support (7 items, e.g., "My family supports me", "Someone in the family helps or has helped me to feel important and special"); misprize (10 items, e.g., "I can make no decision on my own", "I am depreciated at home"); and abuse (emotional and physical, 7 items, e.g., "Were you ever hit by someone in your family or have you experienced physical violence in your family?"). All items were assessed on a 4- or 5-point Likert scale. The four dimensions - closeness, support, misprize, and abuse - were combined into two higher order scales of warmth (Closeness and Support) and maltreatment (Misprize and Abuse). Subjects were divided into low and high (warmth and maltreatment) groups by median split.

\subsubsection{Outcomes}

(i) Aggressive and antisocial behaviors were assessed at mean age 25 using the Buss-Perry Aggression Questionnaire (BPAQ, Buss and Perry, 1992), the Life History of Aggression Interview (LHA, Coccaro et al., 1997), and the Illinois Bully Scale (IBS, Espelage and Holt, 2001). The Buss-Perry questionnaire comprises 29-items and measures Physical aggression, Verbal aggression, Hostility and Anger. The LHA is a 11 item measure of aggression with three subscales: Aggression (including temper tantrums, verbal aggression, indirect aggression, non-specific fighting, and physical assault against people), Consequences/Antisocial behavior (school disciplinary problems, problems with supervisors, 
antisocial behavior not resulting in police involvement, and antisocial behavior involving the police); and Self-directed aggression (self-injurious behavior, and suicide attempts). All items were rated on a 5-point scale. The Illinois Bully Scale is an 18 item, self-report measure that contains three subscales for measuring the frequency of Fighting, Victimization, and Bullying behavior. Participants retrospectively rated bullying, victimization and fighting behaviors around age 15 for self and classmates on a 5-point Likert scale. For rating classmates, participants were first asked to pick the first one or two subjects they remembered well from the list of classmates. The list was narrowed gradually, and when raters could not make a decision, they were asked to pick someone from the list of already rated subjects. The scores were averaged in case of more than one rating per subject. (ii) ADHD symptoms were assessed by teachers at ages $9(n=493), 15(n=402)$ and $18(n=227)$ as described in Kiive et al. (2010) using the 7-point Hyperactivity Scale (af Klinteberg and Oreland, 1995). Information was available on Motor restlessness, Concentration difficulties, and Aggressiveness. Hyperactivity measures were calculated by summing Concentration difficulties and Motor restlessness scores. (iii) Anxious-depressive symptoms were assessed as follows. Symptoms of anxiety were assessed at ages 15 (only State anxiety, $n=449$ ), 18 $\left(\mathrm{n}_{\text {State }}=445, \mathrm{n}_{\text {Trait }}=439\right)$ and $25\left(\mathrm{n}_{\text {State }}=423, \mathrm{n}_{\text {Trait }}=422\right)$ with the Spielberger State Trait Anxiety Inventory (STAI, Spielberger, 1983). Depressive symptoms were assessed with selfreports on the Montgomery-Åsberg Depression Rating Scale (MÅDRS; Montgomery and Åsberg, 1979) at age $18(\mathrm{n}=421)$ and $25(\mathrm{n}=425)$. Further, lifetime presence of mood disorders at age 25 was determined with the Mini-International Neuropsychiatric Interview (M.I.N.I.5.0.0; Shehan et al., 1998) and according to DSM-IV criteria by experienced psychologists. (iv) Behavioral traits were assessed at age 25 with the short version of the Affective Neuroscience Personality Scales (ANPS-S; Pingault et al., 2012). The ANPS-S is 
used to measure participants' behavioral traits on 6 affective - systems (Play, Seek, Care, Fear, Anger, and Sadness).

\subsection{Analyses}

Fisher's exact test was used to determine genotype distributions between psychiatric disorders. Analysis of variance (ANOVA) was used to determine group differences in aggressive, impulsive and anxiousdepressive outcomes. First, differences between CRHRI genotypes were assessed. Next, interactions of genotype with stress and sex were included to assess if type of stress and sex influenced effects of genotype on adolescent and young adult outcomes. For all interactions that were significant, additional post-hoc tests were carried out to assess specific group differences.

\section{Results}

We found no effects of $C R H R I$ genotype or CRHRI-by-sex interactions on adolescent or young adult outcomes. However, two-way $C R H R 1$-by-environment interactions and threeway CRHR1-by-sex-byenvironment interactions were associated with a number of outcomes and are reported below.

\subsection{Aggression and antisocial behaviors}

CRHRl-by-family warmth interaction showed a significant association with Buss Perry subscales of Anger $\left(\mathrm{F}_{(1,354)}=4.56, \mathrm{p}=0.033, \eta^{2}=0.013\right)$ and Hostility $\left(\mathrm{F}_{(1,354)}=6.63, \mathrm{p}=\right.$ $\left.0.011, \eta^{2}=0.018\right)$. Low family warmth was associated with Anger and Hostility in participants with the GG genotype (Fig. 1A). We found no effects on outcomes of Physical or Verbal aggression. Further, no associations were found between CRHRl-by-SLE interaction and outcomes assessed with the Buss-Perry questionnaire. 
We found no effects of two-way or three-way CRHRl interactions on risk for peer-reported Aggression or Victimization, assessed with the Illinois Bully Scale. However, in an exploratory analysis, we found an effect of $C R H R l$-by-SLE interaction on risk for peernominated Victimization in males only $\left(F_{(1,182)}=5.32, p=0.022, \eta^{2}=0.028\right)$. Similar to results from aggressive outcomes, the higher risk for victimization with SLEs was found in males carrying the A-allele (Fig. 1B).
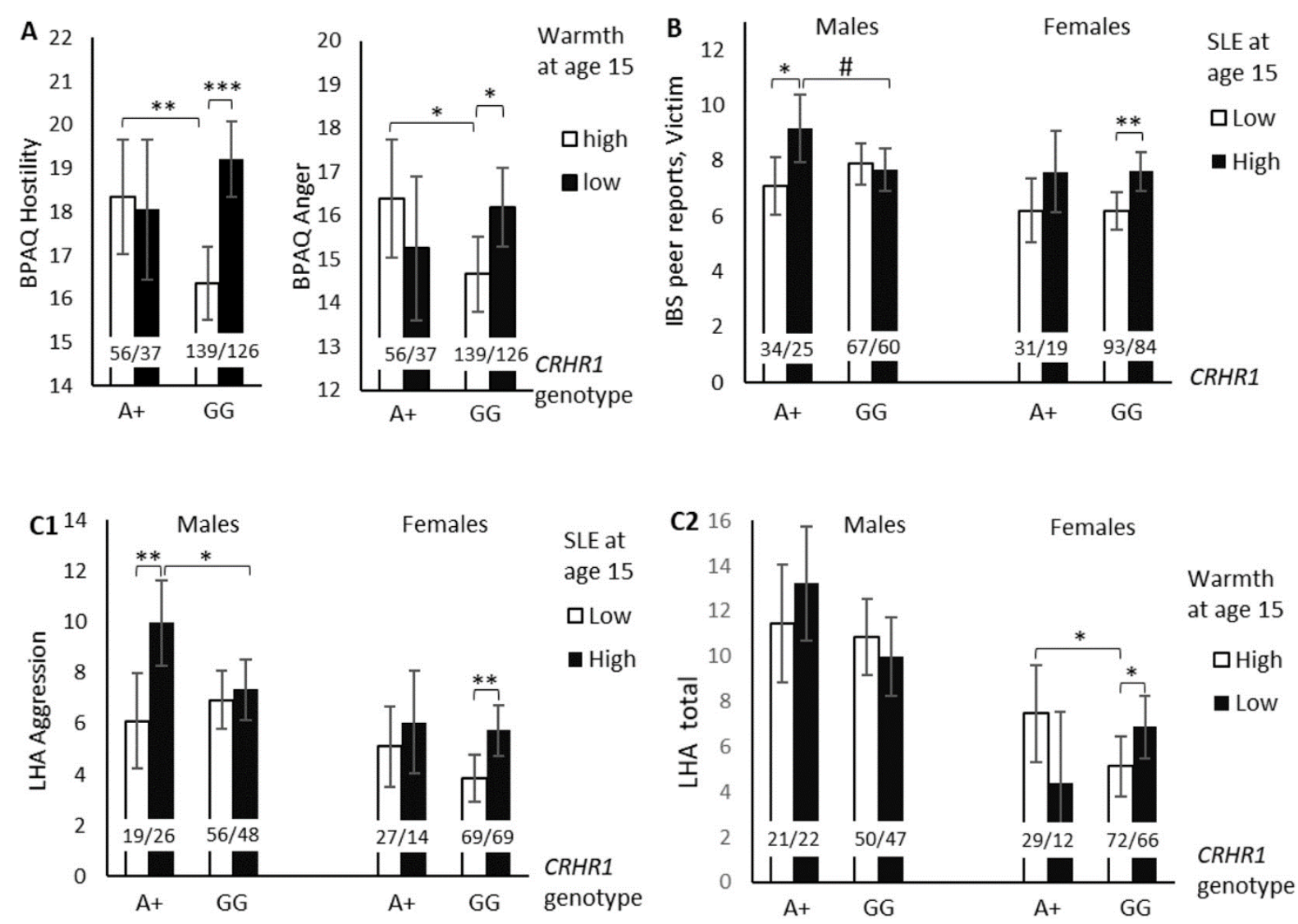

Fig. 1. CRHRI effects by environment or by environment and Sex on Buss-Perry Aggression Questionnaire (BPAQ) Hostility and Anger (A); Illinois Bully Scale (IBS) peer-reported Victimization (B); and on Life History of Aggression interview (LHA) Aggression and the Total scores. \# - $\mathrm{p}=0.068 ; *-\mathrm{p}<0.05, * *-\mathrm{p}<0.01, * * *<0.001$ - differences between indicated groups. Whiskers indicate $95 \%$ confidence intervals.

We found effects of CRHR1-by-sex-by-family warmth interactions on the LHA Aggression subscale $\left(\mathrm{F}_{(1,347)}=4.97, \mathrm{p}=0.026, \eta^{2}=0.014\right)$ and LHA total scores $\left(\mathrm{F}_{(1,347)}=5.76, \mathrm{p}=\right.$ $\left.0.017, \eta^{2}=0.016\right)$. Results from post-hoc tests showed that low family warmth was associated with higher aggression in males carrying the A-allele and females with the GG 
genotype (Fig. 1C). We also found an association between CRHRl-by-sex-by-SLE interaction and scores on the Aggression subscale of the LHA $\left(F_{(1,356)}=4.30, p=0.039, \eta^{2}=\right.$ 0.012). Post-hoc testing showed that high stress was associated with greater aggression scores in males with the A-allele and females with the GG genotype.

\subsection{ADHD}

We found no effects of CRHRl-by-environment interactions on ADHD symptoms. However, CRHRI-by-sex-by-family maltreatment $\left(\mathrm{F}_{(1,189)}=7.20, \mathrm{p}=0.008, \mathrm{\eta}^{2}=0.037\right)$ and CRHRIby-sex-by-SLE $\left(\mathrm{F}_{(1,200)}=4.19, \mathrm{p}=0.042, \eta^{2}=0.021\right)$ were associated with Aggressiveness symptoms at age 18 as assessed with the af Klinteberg 7-point hyperactivity scale. Post-hoc tests showed higher aggression in A-allele males and GG females with higher maltreatment or SLEs (Fig. 2). Further, we found associations between CRHRl-by-sex-by-family maltreatment interaction and motor restlessness at age 18 years $\left(\mathrm{F}_{(1,189)}=7.34, \mathrm{p}=0.007, \mathrm{\eta}^{2}\right.$ $=0.037)$. We found no genotype-related effects on Concentration difficulties at any age.
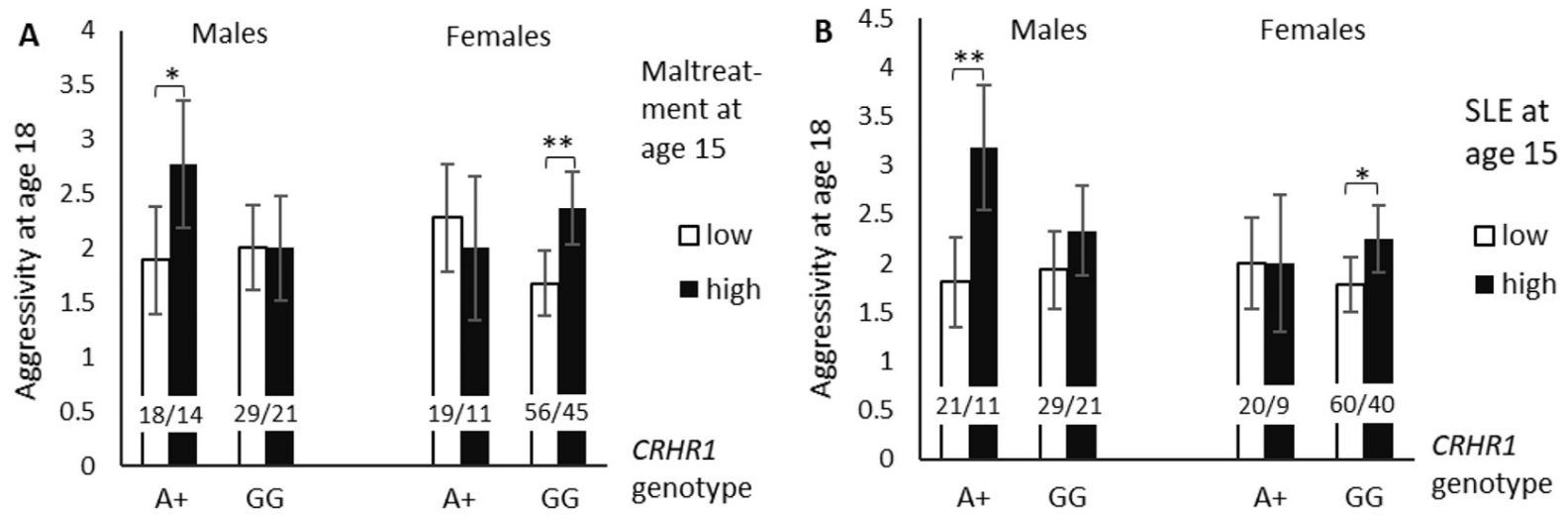

Fig. 2. $C R H R 1 \times$ Sex $\times$ environment effects on af Klinteberg hyperactivity scale Aggressivity: $G \times$ Sex $\times$ Maltreatment (A) and G $\times \operatorname{Sex} \times \operatorname{SLE}(B) . *-p<0.05, * *-p<0.01-$ differences between indicated groups. Whiskers indicate $95 \%$ confidence intervals.

\subsection{Anxious and depressive symptomatology}

We found an association of the CRHRI-by-sex-by-SLE interaction with depressive scores at age $18\left(\mathrm{~F}_{(1,348)}=5.10, \mathrm{p}=0.024, \eta^{2}=0.014\right)$, but not age 25 as per the MADRS reports. Aallele males and GG females with higher SLEs reported greater depressiveness (Fig. 3A). 

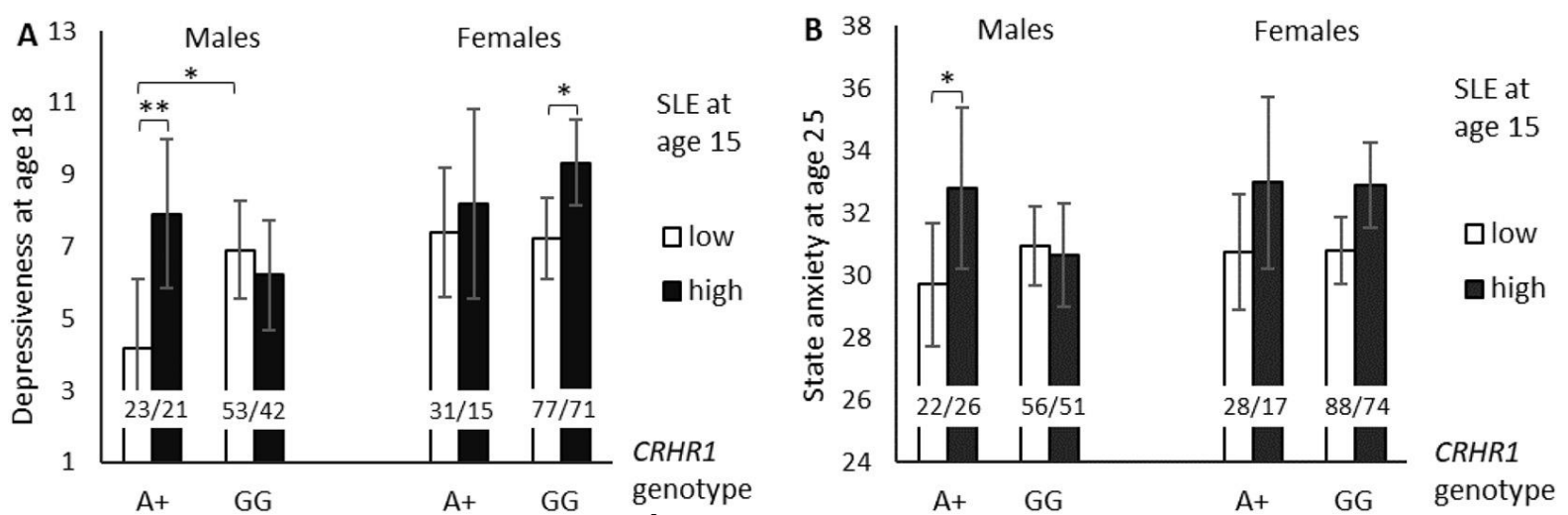

Fig. 3. $C R H R 1 \times \operatorname{Sex} \times$ SLE effects on MÅDRS depressiveness (A) and STAI State anxiety (B). * - p $<0.05$, $* *-\mathrm{p}<0.01, * * *<0.001$ - differences between indicated groups. Whiskers indicate $95 \%$ confidence intervals.

CRHRI-by-sex-by-SLE interactions were significantly associated with State, but not Trait, anxiety as assessed by STAI, at ages $18\left(\mathrm{~F}_{(1,362)}=3.98, \mathrm{p}=0.047, \eta^{2}=0.011\right)$ and $25\left(\mathrm{~F}_{(1,352)}\right.$ $\left.=4.59, \mathrm{p}=0.033, \eta^{2}=0.013\right)$. Males with the A-allele and higher SLE showed higher State anxiety scores at both age 18 and age 25 (Fig. 3B). No effects on State anxiety were found in females.

CRHRl-by-sex-by-SLE interactions were associated with the prevalence of mood disorders assessed by the MINI in males (in low SLE group $\mathrm{p}=0.039$, in high $\mathrm{p}=0.442$ ). Low SLE was associated with a lower risk for depression in males with the GG genotype (Fig. 4). No effects on mood disorders were found in females $\left(\mathrm{p}_{\text {(in low SLE group })}=0.625, \mathrm{p}_{(\mathrm{in} \mathrm{high})}=0.598\right)$.

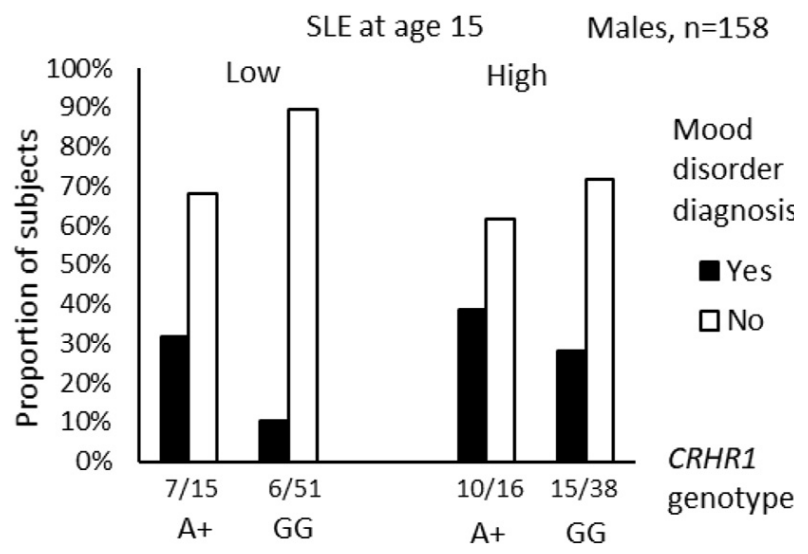

Fig. 4. $C R H R I \times$ SLE effect on the prevalence of mood disorders assessed by MINI in males: Males with the GG genotype had the lowest odds $(\mathrm{OR}=0.25(0.07 ; 0.87)$ for developing a mood disorder in the low-SLE group. 


\subsection{Behavioral traits}

No associations were found between $C R H R l$-by-environment interactions and behavioral traits as per the ANPS-S. Results showed an effect of CRHRl-by-sex-by-SLE interaction on Seeking subscale $\left(\mathrm{F}_{(1,356)}=5.08, \mathrm{p}=0.025, \eta^{2}=0.014\right)$. Post-hoc testing showed that males with the A-allele and higher number of stressful life events had the lowest Seeking scores (Fig. 5).

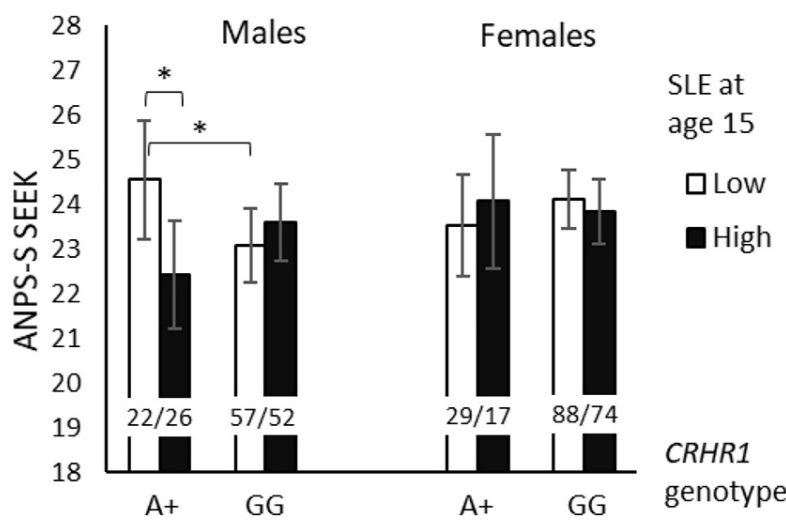

Fig. 5. $C R H R I \times$ Sex $\times$ SLE effect on ANPS-S subscale SEEK. * - $\mathrm{p}<0.05$ - differences between indicated groups. Whiskers indicate $95 \%$ confidence intervals.

\section{Discussion}

Using a large population-based cohort, we aimed to understand the effects of $C R H R I$ rs 17689918 and its interaction with SLE, family maltreatment, and family warmth on mental health and behavioural outcomes in late adolescence and young adulthood. Further, we aimed to assess if the effects of CRHRI differed by type of environment (high SLE, high family maltreatment, or low familial warmth) and sex. In general, our results support a higher susceptibility for poor outcomes in males carrying the A-allele and females with the GG variant given an early negative environment. We also found evidence to suggest that the type of environmental stressor may influence the effects of CRHRI variants on adolescent and adult outcomes.

Previous studies on $C R H R I$ have mainly focussed on its role in depressive outcomes and fewer studies have assessed effects on self-directed aggression. Here, we additionally 
demonstrate an effect of $C R H R 1$ on the risk for outwardly-directed aggression, including anger and hostility. The interaction of stress (in adolescence) with CRHRl is associated with prospective aggressive outcomes. As hypothesized we found an effect of sex where males with the A-allele showed a greater predisposition for aggressive behaviour outcomes. In contrast, risk for aggression was higher in females with the GG genotype, but not A-allele, in presence of a negative environment.

In two previous studies, the rs110402 A-allele was shown to have a protective effect against major depressive disorder in both males and females exposed to childhood abuse (Bradley et al., 2008; Polanczyk et al., 2009). In our study, the risk for depressive problems was higher in males with the rs 17689918 A-allele, and in females with the GG variant. The risk for poor anxiety outcomes in presence of early stress was seen exclusively in males with the A-allele. Taken together with our results on aggressive outcomes, this suggests varied effects of CRHRI variants in the two sexes.

The effects of CRHRI on ADHD and peer problems were less clear. We found some evidence to suggest that $C R H R 1$ interacts with early stress interactions to influence motor restlessness and susceptibility to victimization. However, we did not find any associations of CRHR1 with concentration difficulties, bullying or antisocial behaviors. The lack of effects on bullying and anti-social behaviors is surprising given that we found clear effects of CRHRl on anger, (LHA) aggression, and hostility. Moreover, as noted in a previous paper from the ECPBHS, these aggressiveness measures - bullying, anti-social behaviors, anger, hostility and LHA aggression - are correlated (Kiive et al., 2017). Further, in Kiive et al. (2017), all aggressiveness measures were associated with GABRA2 (Gamma-aminobutyric acid receptor 2) genotype. This suggests that the GABA-A receptor may be more generally associated with aggressiveness than the $\mathrm{CRH}$ receptor. 
It is possible that $C R H R 1$ affects selective dimensions of aggression. For example, differential effects on callous unemotional traits, proactive or reactive aggression, may partly explain the variance in effects on aggression versus antisocial behaviors. It is known that aggressive behaviors in mood disorders are associated with increased HPA axis activity and hypercortisolism (Veenema, 2009). This form of aggression may be reactive or impulsive which is a defensive response to provocation, and which differs from the proactive or premediated aggression common in conduct and personality disorders (Kempes et al., 2005). HPA responses also differ in conduct/personality disorder-associated aggression, showing low HPA axis activity and hypocortisolism (Veenema, 2009). Given that the CRHRI rs 17689918 was associated with both mood problems and aggression in our sample, we can speculate that an associated increase in HPA axis functioning and hypercortisolism may underlie the behavioral outcomes reported. That is, aggression mediated by the CRHRI could be of the reactive or impulsive type. Notably, $\mathrm{CRH}$ and $C R H R 1$ variants have been reported to moderate fear conditioning responses, in turn leading to heightened anxiety (Bijlsma et al., 2011; Heitland et al., 2016; Roozendaal et al., 2002; Thoeringer et al., 2012). Since aggression in response to fear conditioning is likely to be reactive, $C R H R l$ may too mediate reactive, but not proactive aggression (Veenema, 2009; Vitiello and Stoff, 1997).

Dissecting the role of $C R H R 1$ is important for understanding aggressive comorbidity, which is common in depression, suicidal ideation, post-traumatic stress disorder, and substance abuse. These disorders are associated with neural structure and functioning problems in the amygdala and the hippocampus; regions that express CRHR1 and are susceptible to CRHR1 modulation in response to stress (Inda et al., 2017; Seo et al., 2008; Veenit et al., 2014). Thus CRHR1 expression and CRHR1 function may present a pathway to the development of aggressive comorbidity. Further, the association of aggression and fear conditioned responses may be dependent on $C R H R 1$, perhaps via alteration of amygdala function (Herry and 
Johansen, 2014). It is already well known that CRH signaling within the hippocampus and amygdala influence fear acquisition and consolidation of fear memories (Kolber et al., 2008; Roozendaal et al., 2002). Recent studies also demonstrate the association of CRHRI polymorphisms with fear responses. For example, the rs878886 has been associated with reduced fear conditioning responses (Heitland et al., 2013; Heitland et al., 2016). The CRHRI rs 17689918, meanwhile, has been associated with fear sensitization and anxious symptoms in fear provocation (Weber et al., 2016). Therefore, further study of CRHRl variants and their modulation of fear responses can provide an operational genetic mechanism that explains fear conditioning and aggressive behavior.

Our results show that $C R H R l$-by-stress interactions predicted lower reward and sensation seeking behavior, exclusively in males with the Aallele. Lower sensation seeking is linked to a higher risk for depression (Panksepp and Watt, 2011). Thus, the effects of CRHRI on depressive outcomes could be mediated by low seeking behaviors, at least in males. This proposition, if confirmed by future studies, would further support a differential effect of CRHRl variants by gender.

There was some evidence to suggest that the type of environmental stress may affect eventual outcome. We hypothesized that low family warmth or high mistreatment in our sample would likely affect aggressive outcomes, while high SLEs would influence the risk for depression. In line with this, our results showed that the risk for mood problems and victimization was predicted only by interactions of CRHR1-by-SLE, and not by interactions of familial warmth with CRHR1. However, both low family warmth and high SLEs were associated with aggressive outcomes. It should be noted though that family warmth was associated with specific dimensions of aggression, such as anger and hostility, while SLEs were more likely to be associated with generalized measures of aggressive outcomes. 
A few limitations to this study warrant attention. First, we did not control for multiple testing which may bias our findings. It has though been noted that the application of a correction for multiple testing may create "more problems than it solves" (Perneger, 1998; Moran, 2003; Nakagawa 2004). Second, stress was assessed in adolescence, but not in childhood. It could be argued that early childhood stress would have a greater effect on mental health. However, cognitive maturation continues well beyond adolescence into early adulthood and any stress during this time could potentially impair mental health outcomes. Thus, our study highlights the effects of such adolescent-onset stress on outcomes. Future research may address effects of childhood and adolescent stress on mental health and further determine if time-dependent effects of stress may explain the widespread effects of $C R H R I$ on mental health. Third, depressed-anxious symptoms and aggressive, antisocial behaviors were not assessed at baseline. Thus, these variables could not be controlled for in our analyses, and the possibility of baseline symptomatology affecting future outcomes cannot be ruled out.

In conclusion, $C R H R l$ variants interact with early stress experience and influence long-term mental health and behavior. Using a longitudinal population-representative cohort, we report that type of stress and sex may moderate the influence of $C R H R 1$ variation on risk for aggressive, anxious, and mood symptoms as well as behavioral traits. Future research should be directed at understanding the developmental effects of $C R H R l$-by-stress interactions. This knowledge has the potential to address developmental trajectory changes subject to HPA system fine-tuning by environmental factors and the effects of such changes on mental health outcomes.

\section{Acknowledgements}

We are grateful to the Estonian Children Personality Behaviour and Health Study (ECPBHS) participants, their parents, and the whole study team. 
This study was supported by the Estonian Ministry of Education and Science ProjectIUT2040, and 42-2, as well as the EC FP7 Project Aggressotype (FP7-Health-2013-Innovation602805). The authors' work was also supported by the European Community (Eat2beNICE H2020/No. 728018), the 5-100 Russian Academic Excellence Project, and by grants from the German Research Foundation (DFG: SFB/ TRR58, Project A05) to Dr. KP Lesch. Dr. A Roy was supported by a Fellowship from the Alexander von Humboldt Foundation.

The authors thank Gabriela Ortega and Dr. Christoph Schartner for excellent technical assistance.

\section{Disclosures}

The authors report no conflicts of interest.

\section{Ethical statement}

The study was approved by the Tartu University Ethics Review Committee on Human Research. Subjects provided written informed consent to participate in the study and all procedures were carried out in accordance with the Declaration of Helsinki.

\section{References}

Bale, T.L., Epperson, C.N., 2015. Sex differences and stress across the lifespan. Nat. Neurosci. 18 (10), 1413-1420.

Bijlsma, E.Y., Van Leeuwen, M.L.F., Westphal, K.G.C., Olivier, B., Groenink, L., 2011. Local repeated corticotropin-releasing factor infusion exacerbates anxiety-and fear-related behavior: differential involvement of the basolateral amygdala and medial prefrontal cortex. Neuroscience 173, 82-92.

Blomeyer, D., Treutlein, J., Esser, G., Schmidt, M.H., Schumann, G., Laucht, M., 2008. Interaction between CRHR1 gene and stressful life events predicts adolescent heavy alcohol use. Biol. Psychiatry 63 (2), 146-151.

Böhnke, R., Bertsch, K., Kruk, M.R., Naumann, E., 2010. The relationship between basal and acute HPA axis activity and aggressive behavior in adults. J. Neural Transm. 117 (5), 629637. 
Bradley, R.G., Binder, E.B., Epstein, M.P., Tang, Y., Nair, H.P., Liu, W., ... Stowe, Z.N., 2008. Influence of child abuse on adult depression: moderation by the corticotropin-releasing hormone receptor gene. Arch. Gen. Psychiatry 65 (2), 190-200.

Bremner, J.D., Narayan, M., Anderson, E.R., Staib, L.H., Miller, H.L., Charney, D.S., 2000. Hippocampal volume reduction in major depression. Am. J. Psychiatr. 157 (1), 115-118.

Buss, A.H., Perry, M., 1992. The aggression questionnaire. J. Pers. Soc. Psychol. 63 (452259).

Chen, B., Gu, T., Ma, B., Zheng, G., Ke, B., Zhang, X., Qiu, J., 2014. The CRHR1 gene contributes to genetic susceptibility of aggressive behavior towards others in Chinese southwest Han population. J. Mol. Neurosci. 52 (4), 481-486.

Coccaro, E.F., Berman, M.E., Kavoussi, R.J., 1997. Assessment of life history of aggression: development and psychometric characteristics. Psychiatry Res. 73 (3), 147-157.

De Luca, V., Tharmalingam, S., Zai, C., Potapova, N., Strauss, J., Vincent, J., Kennedy, J.L., 2010. Association of HPA axis genes with suicidal behaviour in schizophrenia. J.

Psychopharmacol. 24 (5), 677-682.

Espelage, D.L., Holt, M.K., 2001. Bullying and victimization during early adolescence: peer influences and psychosocial correlates. J. Emot. Abus. 2 (2-3), 123-142.

Frodl, T., Meisenzahl, E.M., Zetzsche, T., Born, C., Groll, C., Jäger, M., ... Möller, H.J., 2002. Hippocampal changes in patients with a first episode of major depression. Am. J. Psychiatr. 159 (7), 1112-1118.

Harro, M., Eensoo, D., Kiive, E., Merenäkk, L., Alep, J., Oreland, L., Harro, J., 2001. Platelet monoamine oxidase in healthy 9-and 15-years old children: the effect of gender, smoking and puberty. Prog. Neuro-Psychopharmacol. Biol. Psychiatry 25 (8), 1497-1511.

Heim, C., Bradley, B., Mletzko, T., Deveau, T.C., Musselmann, D.L., Nemeroff, C.B., ... Binder, E.B., 2009. Effect of childhood trauma on adult depression and neuroendocrine function: sex-specific moderation by CRH receptor 1 gene. Front. Behav. Neurosci. 3, 41.

Heitland, I., Groenink, L., Bijlsma, E.Y., Oosting, R.S., Baas, J.M., 2013. Human fear acquisition deficits in relation to genetic variants of the corticotropin releasing hormone receptor 1 and the serotonin transporter. PLoS One 8 (5), e63772.

Heitland, I., Groenink, L., van Gool, J.M., Domschke, K., Reif, A., Baas, J.M.P., 2016. Human fear acquisition deficits in relation to genetic variants of the corticotropin-releasing hormone receptor 1 and the serotonin transporter-revisited. Genes Brain Behav. 15 (2), 209-220.

Herry, C., Johansen, J.P., 2014. Encoding of fear learning and memory in distributed neuronal circuits. Nat. Neurosci. 17 (12), 1644.

Holmes, M.R., 2013. Aggressive behavior of children exposed to intimate partner violence: an examination of maternal mental health, maternal warmth and child maltreatment. Child Abuse Negl. 37 (8), 520-530.

Holsboer, F., 2000. The corticosteroid receptor hypothesis of depression.

Neuropsychopharmacology 23 (5), 477-501.

Inda, C., Armando, N.G., dos Santos Claro, P.A., Silberstein, S., 2017. Endocrinology and the brain: corticotropin-releasing hormone signaling. Endocrine Connect. 6 (6), R99-R120. 
Ivy, A.S., Rex, C.S., Chen, Y., Dubé, C., Maras, P.M., Grigoriadis, D.E., ... Baram, T.Z., 2010. Hippocampal dysfunction and cognitive impairments provoked by chronic early-life stress involve excessive activation of CRH receptors. J. Neurosci. 30 (39), 13005-13015.

Kempes, M., Matthys, W., De Vries, H., Van Engeland, H., 2005. Reactive and proactive aggression in children a review of theory, findings and the relevance for child and adolescent psychiatry. Eur. Child Adolesc. Psychiatry 14 (1), 11-19.

Kiive, E., Kurrikoff, T., Mäestu, J., Harro, J., 2010. Effect of a 2A-adrenoceptor C-1291G genotype and maltreatment on hyperactivity and inattention in adolescents. Prog. NeuroPsychopharmacol. Biol. Psychiatry 34 (1), 219-224.

Kiive, E., Laas, K., Vaht, M., Veidebaum, T., Harro, J., 2017. Stressful life events increase aggression and alcohol use in young carriers of the GABRA2 rs279826/rs279858 A-allele. Eur. Neuropsychopharmacol. 27, 816-827.

Klinteberg, B., Oreland, L., 1995. Hyperactive and aggressive behaviors in childhood as related to low platelet monoamine oxidase (MAO) activity at adult age: a longitudinal study of male subjects. Personal. Individ. Differ. 19 (3), 373-383.

Kolber, B.J., Roberts, M.S., Howell, M.P., Wozniak, D.F., Sands, M.S., Muglia, L.J., 2008. Central amygdala glucocorticoid receptor action promotes fear-associated CRH activation and conditioning. Proc. Natl. Acad. Sci. 105 (33), 12004-12009.

Laas, K., Reif, A., Kiive, E., Domschke, K., Lesch, K.P., Veidebaum, T., Harro, J., 2014. A functional NPSR1 gene variant and environment shape personality and impulsive action: a longitudinal study. J. Psychopharmacol. 28 (3), 227-236.

Liao, X.M., Yang, X.D., Jia, J., Li, J.T., Xie, X.M., Su, Y.A., ... Wang, X.D., 2014. Blockade of corticotropin-releasing hormone receptor 1 attenuates early-life stress-induced synaptic abnormalities in the neonatal hippocampus. Hippocampus 24 (5), 528-540.

Liaw, C.W., Lovenberg, T.W., Barry, G., Oltersdorf, T., Grigoriadis, D.E., de Souza, E.B., 1996. Cloning and characterization of the human corticotropin-releasing factor-2 receptor complementary deoxyribonucleic acid. Endocrinology 137 (1), 72-77.

Liu, Z., Zhu, F., Wang, G., Xiao, Z., Wang, H., Tang, J., Li, W., 2006. Association of corticotropin-releasing hormone receptor1 gene SNP and haplotype with major depression. Neurosci. Lett. 404 (3), 358-362.

Liu, Z., Zhu, F., Wang, G., Xiao, Z., Tang, J., Liu, W., Cao, Z., 2007. Association study of corticotropin-releasing hormone receptor 1 gene polymorphisms and antidepressant response in major depressive disorders. Neurosci. Lett. 414 (2), 155-158.

Liu, R., Yang, X.D., Liao, X.M., Xie, X.M., Su, Y.A., Li, J.T., ... Si, T.M., 2016. Early postnatal stress suppresses the developmental trajectory of hippocampal pyramidal neurons: the role of CRHR1. Brain Struct. Funct. 221 (9), 4525-4536.

Merali, Z., Du, L., Hrdina, P., Palkovits, M., Faludi, G., Poulter, M.O., Anisman, H., 2004. Dysregulation in the suicide brain: mRNA expression of corticotropin-releasing hormone receptors and GABAA receptor subunits in frontal cortical brain region. J. Neurosci. 24 (6), $1478-1485$.

Montgomery, S.A., Åsberg, M., 1979. A new depression scale designed to be sensitive to change. Br. J. Psychiatry 134 (4), 382-389.

Moran, M.D., 2003. Arguments for rejecting the sequential Bonferroni in ecological studies. Oikos 100 (2), 403-405. 
Müller, M.B., Zimmermann, S., Sillaber, I., Hagemeyer, T.P., Deussing, J.M., Timpl, P., ... Holsboer, F., 2003. Limbic corticotropin-releasing hormone receptor 1 mediates anxietyrelated behavior and hormonal adaptation to stress. Nat. Neurosci. 6 (10), 1100.

Nakagawa, S., 2004. A farewell to Bonferroni: the problems of low statistical power and publication bias. Behav. Ecol. 15 (6), 1044-1045.

Nemeroff, C.B., Owens, M.J., Bissette, G., Andorn, A.C., Stanley, M., 1988. Reduced corticotropin releasing factor binding sites in the frontal cortex of suicide victims. Arch. Gen. Psychiatry 45 (6), 577-579.

Nestler, E.J., Barrot, M., DiLeone, R.J., Eisch, A.J., Gold, S.J., Monteggia, L.M., 2002. Neurobiology of depression. Neuron 34 (1), 13-25.

Ngun, T.C., Ghahramani, N., Sánchez, F.J., Bocklandt, S., Vilain, E., 2011. The genetics of sex differences in brain and behavior. Front. Neuroendocrinol. 32 (2), 227-246.

Paaver, M., Kurrikoff, T., Nordquist, N., Oreland, L., Harro, J., 2008. The effect of 5-HTT gene promoter polymorphism on impulsivity depends on family relations in girls. Prog. Neuro-Psychopharmacol. Biol. Psychiatry 32 (5), 1263-1268.

Panksepp, J., Watt, D., 2011. Why does depression hurt? Ancestral primary-process separation-distress (PANIC/GRIEF) and diminished brain reward (SEEKING) processes in the genesis of depressive affect. Psychiatry 74 (1), 5-13.

Pariante, C.M., Miller, A.H., 2001. Glucocorticoid receptors in major depression: relevance to pathophysiology and treatment. Biol. Psychiatry 49 (5), 391-404.

Perneger, T.V., 1998. What's wrong with Bonferroni adjustments. BMJ 316 (7139), 1236.

Pingault, J.B., Falissard, B., Côté, S., Berthoz, S., 2012. A new approach of personality and psychiatric disorders: a short version of the affective neuroscience personality scales. PLoS One 7 (7), e41489.

Polanczyk, G., Caspi, A., Williams, B., Price, T.S., Danese, A., Sugden, K., Moffitt, T.E., 2009. Protective effect of CRHR1 gene variants on the development of adult depression following childhood maltreatment: replication and extension. Arch. Gen. Psychiatr. 66 (9), 978-985.

Power, R.A., Cohen-Woods, S., Ng, M.Y., Butler, A.W., Craddock, N., Korszun, A., ... Maier, W., 2013. Genome-wide association analysis accounting for environmental factors through propensity-score matching: application to stressful live events in major depressive disorder. Am. J. Med. Genet. B Neuropsychiatr. Genet. 162 (6), 521-529.

Preil, J., Müller, M.B., Gesing, A., Reul, J.M., Sillaber, I., Van Gaalen, M.M., ... Wurst, W., 2001. Regulation of the hypothalamic-pituitary-adrenocortical system in mice deficient for CRH receptors 1 and 2. Endocrinology 142 (11), 4946-4955.

Ressler, K.J., 2010. Amygdala activity, fear, and anxiety: modulation by stress. Biol. Psychiatry 67 (12), 1117-1119.

Ressler, K.J., Bradley, B., Mercer, K.B., Deveau, T.C., Smith, A.K., Gillespie, C.F., ... Binder, E.B., 2010. Polymorphisms in CRHR1 and the serotonin transporter loci: genex genex environment interactions on depressive symptoms. Am. J. Med. Genet. B Neuropsychiatr. Genet. 153 (3), 812-824.

Roozendaal, B., Brunson, K.L., Holloway, B.L., McGaugh, J.L., Baram, T.Z., 2002. Involvement of stress-released corticotropin-releasing hormone in the basolateral amygdala in regulating memory consolidation. Proc. Natl. Acad. Sci. 99 (21), 13908-13913. 
Schmid, B., Blomeyer, D., Treutlein, J., Zimmermann, U.S., Buchmann, A.F., Schmidt, M.H., ... Laucht, M., 2010. Interacting effects of CRHR1 gene and stressful life events on drinking initiation and progression among 19-year-olds. Int. J. Neuropsychopharmacol. 13 (6), 703-714.

Seo, D., Patrick, C.J., Kennealy, P.J., 2008. Role of serotonin and dopamine system interactions in the neurobiology of impulsive aggression and its comorbidity with other clinical disorders. Aggress. Violent Behav. 13 (5), 383-395.

Shehan, D.V., Lecrubier, Y., Sheehan, K.H., Amorim, P., Janvas, J., Weiller, E., ... Dunbar, G.C., 1998. The Mini-International Neuropsychiatric Interview (MINI): the development and validation of a structered psychiatric interview for DSM-IV and ICD-10. J. Clin. Psychiatry 59 (S20), 22-33.

Da Silva, B.S., Rovaris, D.L., Schuch, J.B., Mota, N.R., Cupertino, R.B., Aroche, A.P., ... Grevet, E.H., 2016. Effects of corticotropin-releasing hormone receptor 1 SNPs on major depressive disorder are influenced by sex and smoking status. J. Affect. Disord. 205, 282288.

Spielberger, C.D., 1983. Manual for the State-Trait Anxiety Inventory STAI (Form Y) ("SelfEvaluation Questionnaire").

Thoeringer, C.K., Henes, K., Eder, M., Dahlhoff, M., Wurst, W., Holsboer, F., ... Wotjak, C.T., 2012. Consolidation of remote fear memories involves Corticotropin-Releasing Hormone $(\mathrm{CRH})$ receptor type 1-mediated enhancement of AMPA receptor GluR1 signaling in the dentate gyrus. Neuropsychopharmacology 37 (3), 787.

Timpl, P., Spanagel, R., Sillaber, I., Kresse, A., Reul, J.M., Stalla, G.K., ... Wurst, W., 1998. Impaired stress response and reduced anxiety in mice lacking a functional corticotropinreleasing hormone receptor 1 . Nat. Genet. 19 (2), 162.

Tomson, K., Merenäkk, L., Loit, H.M., Mäestu, J., Harro, J., 2011. The relationship between serotonin transporter gene promoter polymorphism and serum lipid levels at young age in a longitudinal population-representative study. Prog. Neuro-Psychopharmacol. Biol. Psychiatry 35 (8), 1857-1862.

Tyrka, A.R., Price, L.H., Gelernter, J., Schepker, C., Anderson, G.M., Carpenter, L.L., 2009. Interaction of childhood maltreatment with the corticotropin-releasing hormone receptor gene: effects on hypothalamic-pituitary-adrenal axis reactivity. Biol. Psychiatry 66 (7), 681685.

Veenema, A.H., 2009. Early life stress, the development of aggression and neuroendocrine and neurobiological correlates: what can we learn from animal models? Front.

Neuroendocrinol. 30 (4), 497-518.

Veenit, V., Riccio, O., Sandi, C., 2014. CRHR1 links peripuberty stress with deficits in social and stress-coping behaviors. J. Psychiatr. Res. 53, 1-7.

Vitiello, B., Stoff, D.M., 1997. Subtypes of aggression and their relevance to child psychiatry. J. Am. Acad. Child Adolesc. Psychiatry 36 (3), 307-315.

Waller, R., Corral-Frías, N.S., Vannucci, B., Bogdan, R., Knodt, A.R., Hariri, A.R., Hyde, L.W., 2016. An oxytocin receptor polymorphism predicts amygdala reactivity and antisocial behavior in men. Soc. Cogn. Affect. Neurosci. 11 (8), 1218-1226. 
Wasserman, D., Sokolowski, M., Rozanov, V., Wasserman, J., 2008. The CRHR1 gene: a marker for suicidality in depressed males exposed to low stress. Genes Brain Behav. 7 (1), $14-19$.

Wasserman, D., Wasserman, J., Rozanov, V., Sokolowski, M., 2009. Depression in suicidal males: genetic risk variants in the CRHR1 gene. Genes Brain Behav. 8 (1), 72-79.

Weber, H., Richter, J., Straube, B., Lueken, U., Domschke, K., Schartner, C., ... Scholz, C.J., 2016. Allelic variation in CRHR1 predisposes to panic disorder: evidence for biased fear processing. Mol. Psychiatry 21 (6), 813. 